\title{
LONG-TERM RESULTS OF RECONSTRUCTIONS OF THE LEFT ANTERIOR DESCENDING CORONARY ARTERY IN DIFFUSE ATHEROSCLEROTIC LESIONS
}

Oğuz Taşdemir, MD ${ }^{a}$

Uğursay Kiziltepe, $\mathrm{MD}^{\mathrm{a}}$

Haldun Y. Karagöz, MD

Birol Yamak, MD

Sule Korkmaz, $\mathrm{MD}^{\mathrm{b}}$

Kemal Bayazit, $\mathrm{MD}^{\mathrm{a}}$
One hundred twenty patients who had diffuse atherosclerotic lesions necessitating reconstruction of the left anterior descending artery with or without open endarterectomy and coronary artery bypass grafting were investigated retrospectively and compared with 130 patients who underwent conventional bypass grafting in the same time frame. Methods: Sixty-one endarterectomies were performed with long arteriotomies (group I) and 59 patch reconstructions were placed over stenosing plaques without an endarterectomy (group II). Patients having only conventional coronary bypass constituted group III. Results: Hospital mortalities were 6.5\%, 5.1\%, and $1.5 \%$ in group I, group II, and group III, respectively ( $p=$ not significant). Five patients in group I (8.1\%), six in group II (10.1\%), and two in group III $(1.5 \%)$ had perioperative myocardial infarction (group II vs group III, $p=0.016$ ). Angiographic restudy of grafts to the left anterior descending system revealed a patency rate of $81.5 \%$ in group $I, 79.1 \%$ in group II, and 94.4\% in group III patients after mean periods of $6.3,5.7$, and 6.1 years, respectively ( $p=$ not significant). Actuarial survivals at 7 years were $94 \% \pm 5.0 \%, 74.8 \% \pm 16 \%$, and $90.9 \% \pm 7.4 \%$ in groups I, II, and III, respectively (group I vs group II, $p=0.007$; group II vs group III, $p=$ 0.008). Freedom from recurrent angina at 7 years was $42.7 \% \pm 15.6 \%$ in group I, 33.5\% $\pm 19 \%$ in group II, and $71.9 \% \pm 14.2 \%$ in group III (group I vs group III, $p=0.03$; group II vs group III, $p=0.0001$ ). Thirty-four percent of patients in group I, 24\% in group II, and $60.4 \%$ in group III were working actively in the late postoperative period $(p=0.0001)$. Conclusion: Extended revascularizations of the left anterior descending coronary artery increase surgical risk, although not to a statistically significant degree, and should be performed only of necessity. However, once needed, revascularization is a lifesaving procedure with acceptable early and long-term results. (J Thorac Cardiovasc Surg 1996;112:745-54)
Sa everal studies indicate that patients with diffuse coronary artery disease (CAD) in whom standard coronary bypass techniques cannot be performed constitute $0.8 \%$ to $25.1 \%$ of all patients with CAD. $^{1-3}$

Endarterectomy and reconstruction of the left anterior descending (LAD) coronary artery is a

From the Departments of Cardiovascular Surgery ${ }^{\mathrm{a}}$ and Cardiology, Türkiye Yüksek İhtisas Hospital, Ankara, Turkey.

Received for publication Feb. 13, 1996; revisions requested March 7, 1996; revisions received March 28, 1996; accepted for publication April 1, 1996.

Address for reprints: Ugursay Kızıltepe, MD, Department of Cardiovascular Surgery, Türkiye Yüksek Ihtisas Hospital, Sihhiye, Ankara 06100, Turkey.

Copyright (C) 1996 by Mosby-Year Book, Inc.

$0022-5223 / 96 \$ 5.00+0 \quad \mathbf{1 2} / \mathbf{1} / 73917$ time-consuming, meticulous, and more challenging procedure than conventional coronary artery bypass grafting (CABG), and its feasibility is controversial. ${ }^{3}$ However, the expansion in the indications for surgical therapy of severe and diffuse CAD has resulted in a revival of interest in coronary artery endarterectomy. ${ }^{4}$ It may be the only therapeutic option for some patients whose condition is otherwise deemed inoperable.

To assess the early and late results of different reconstruction techniques of the $\mathrm{LAD}$ artery, we retrospectively investigated and presented the case histories of 250 patients in three groups.

\section{Patients and methods}

Between 1988 and 1992, 4200 patients with CAD underwent myocardial revascularization at this institution. 
Table I. Preoperative characteristics of patients

\begin{tabular}{|c|c|c|c|}
\hline & Group $I$ & Group II & Group III \\
\hline No. of patients & 61 & 59 & 130 \\
\hline Female $(\%)$ & 11 & 10 & 13 \\
\hline Mean age (yr) & $53.6 \pm 13.7$ & $54.2 \pm 12.3$ & $54.7 \pm 11.8$ \\
\hline Class I (\%) & 8 & 5.1 & 3 \\
\hline Class II (\%) & 46 & 54.2 & 57 \\
\hline Class III (\%) & 36 & 32.2 & 28 \\
\hline Class IV $(\%)$ & 10 & 8.5 & 12 \\
\hline $\begin{array}{l}\text { One-vessel disease } \\
(\%)\end{array}$ & 8 & 10 & 13 \\
\hline $\begin{array}{l}\text { Two-vessel disease } \\
(\%)\end{array}$ & 33 & 25 & 32 \\
\hline $\begin{array}{l}\text { Three-vessel dis- } \\
\text { ease }(\%)\end{array}$ & 59 & 65 & 55 \\
\hline $\begin{array}{l}\text { Severe LV dys- } \\
\text { function }(\%)\end{array}$ & 13 & 7 & 5.4 \\
\hline Hypertension (\%) & 26 & 27 & 28 \\
\hline Smoking (\%) & $57\left(p=0.03^{*}\right)$ & $56(p=0.043 \dagger)$ & 39 \\
\hline Diabetes (\%) & 21 & $28(p=0.005 \dagger)$ & 10 \\
\hline $\begin{array}{l}\text { Family history } \\
(\%)\end{array}$ & 28 & 15 & 18 \\
\hline $\begin{array}{l}\text { Hyperlipidemia } \\
(\%)\end{array}$ & 34 & 32 & 45 \\
\hline Obesity (\%) & 5 & 4 & 7 \\
\hline
\end{tabular}

Class, Clinical angina class of patients according to the Canadian Cardiovascular Society; $L V$, left ventricular. Only statistically significant $p$ values are indicated.

${ }^{*}$ Group I versus group III

†Group II versus group III.

One hundred twenty patients $(3 \%)$ required isolated patch reconstruction of the LAD artery with or without coronary endarterectomy. Sixty-one patients underwent LAD artery endarterectomy under direct vision with long arteriotomies (group I); 59 were subjected to LAD artery patch reconstructions placed over stenosing plaques without an endarterectomy (group II). For comparison, a control group including 130 patients (group III) was constituted randomly among patients subjected to standard $\mathrm{CABG}$ techniques during the same time period and by the same surgical teams. There was one reoperation in both group I and group III.

Patients who underwent additional endarterectomies and reconstructions of arteries other than the LAD artery, as well as accompanying procedures such as left ventricular aneurysmectomy or valve replacement, were excluded from the study groups. Preoperative characteristics of the groups are depicted in Table I.

Surgical procedure. Standard median sternotomy and aorta-right atrial cannulation were performed after cardiopulmonary bypass was instituted. Patients were cooled to $29^{\circ}$ to $31^{\circ} \mathrm{C}$ and cold saline solution was used intrapericardially for topical cooling of the myocardium. Revascularization procedures were performed with aortic crossclamping and cardioplegic arrest. Myocardial protection was achieved by induction of cardioplegia with cold crystalloid cardioplegic solution followed by a combina-
Table II. Operative characteristics of all three groups

\begin{tabular}{lccc}
\hline & Group I & Group II & Group III \\
\hline $\begin{array}{l}\text { Mean No. of } \\
\quad \text { anastomoses }\end{array}$ & $2.7 \pm 0.4$ & $3.1 \pm 0.9$ & $2.9 \pm 0.3$ \\
Mean length of & $7.1 \pm 1.8$ & $4.3 \pm 1.2$ & - \\
$\quad$ reconstruction (cm) & & & \\
ITA PP & 48 & 56 & - \\
ITA+SV PP & 6 & 0 & - \\
Ao-SV PP & 7 & 3 & - \\
Reoperation & 1 & 0 & 1 \\
Free ITA & 3 & 2 & 5 \\
\hline
\end{tabular}

$I T A P P, \mathrm{LAD}$ artery reconstructions with ITA; ITA $+S V P P, \mathrm{LAD}$ artery reconstruction with saphenous vein patch and an ITA anastomosis; $A O-S V$ $P P$, aorta-LAD artery saphenous bypass and patch reconstruction.

tion of antegrade plus retrograde blood cardioplegia, and cardioplegic arrest was terminated by a terminal dose of retrograde warm blood cardioplegia.

Group I. If the atherosclerotic process involved the distal LAD artery or obstructed the intermediate, septal, and diagonal tributaries and there was no suitable place to construct a conventional anastomosis, a long arteriotomy was made and extended until nondiseased arterial lumen was reached. If the diffuse occlusion included the main septal perforator artery, occasionally the arteriotomy was extended more proximally to this level and the ostium was exposed. If the occlusion extended into the diagonal artery, the arteriotomy was extended until the end of plaque was reached.

After arteriotomy, the cleavage between the plaque and vessel wall was found. They were gently separated, and the atherosclerotic material was removed under direct vision without traction or countertraction of the endarterectomy core. No special device was used. Margins of endarterectomy specimens were examined carefully to see whether the distal end tapered or feathered. If the end was not tapered, the arteriotomy was extended toward the apex and residual atherosclerotic material was removed.

It was deemed crucial to avoid residual dissecting layers and not to leave residual plaques with separated ends. Once an ideal plane was established, plaques at the openings of septal perforators were easily removed with good tapering ends because continuities of atheromatous core at septal arteries generally were not longer than $0.5 \mathrm{~cm}$.

After establishment of a smooth lumen free of atherosclerotic material, three different techniques of reconstruction were used (Table II).

1. If the internal thoracic artery (ITA) was long enough, an extended patch anastomosis was constructed over the arteriotomy alone with a single running 7-0 or 8-0 polypropylene suture. During the procedure care was taken to rebuild a new artery with an optimal diameter not much wider than that of the native healthy artery to avoid the unfavorable hemodynamic effects of diameter discrepancies. This procedure was performed on 48 patients. Three patients had an ITA shorter than needed and these grafts were used as free grafts. 
2. Six long arteriotomies were closed with a longitudinally opened saphenous vein segment with a single running 7-0 or 8-0 polypropylene suture. Care was taken to avoid creating too patulous a lumen. After reconstruction, an ITA graft was anastomosed onto the saphenous vein patch.

3. In nine patients, the ITA was not used and an aorta-coronary saphenous vein bypass graft was constructed over an extended arteriotomy of the LAD artery by means of the same method.

Group II. If the patient had additional stenosing plaque or plaques localized distally and an endarterectomy seemed unnecessary, a long arteriotomy over occlusive plaque or plaques was preferred. The artery was reconstructed with a patch rather than multiple anastomoses proximal and distal to this plaque. This technique was used in 59 patients. In 56 patients an ITA graft was used as an onlay patch, and in two of them the ITA was used as a free graft; three arteries were reconstructed with the distal end of the aorta-LAD saphenous vein bypass graft.

Postoperative care was routine. Dipyridamole $75 \mathrm{mg}$ three times a day and $250 \mathrm{mg}$ acetylsalicylic acid daily were given in the postoperative period after removal of the chest tubes. Anticoagulants were not used. Special emphasis was given to early diagnosis of myocardial ischemia as evidenced by the electrocardiogram, measurements of myocardial isoenzymes, and the clinical status of the patients. Attention was paid to the location of the infarction, whether it was a result of an occlusion of endarterectomized or reconstructed artery or an occlusion of another artery that had been revascularized with a standard anastomosis. As soon as a perioperative myocardial infarction was documented, heparin (1000 IU/hr) and nitroglycerin were given intravenously. An intraaortic balloon pump was inserted if necessary.

Data analysis and follow-up. Anginal status of patients was classified as described by the Canadian Cardiovascular Society and analyzed before and after the operation. ${ }^{5}$ Perioperative myocardial infarction was defined as persistent electrocardiographic changes as described by The Minnesota Code. ${ }^{6}$ All patients received follow-up examinations 2 months and 8 months after the operation and yearly thereafter. Follow-up was completed with patient questionnaires and direct contact by telephone. Anginal status, postoperative late myocardial infarction, interventions (such as coronary angiography), and working status were determined at late follow-up. Patients who had recurrent chest pain were restudied angiographically-38 patients (64\%) in group I, 24 in group II (42\%), and 18 in group III (14\%).

Actuarial survival and actuarial freedom from recurrent angina with $95 \%$ confidence limits were calculated with the life-table method. ${ }^{7,8}$ Difference of proportions was compared by a test for comparing two proportions and by the $\chi^{2}$ test. A $p$ value less than 0.05 was assumed to indicate statistical significance.

\section{Results}

All groups were similar with respect to demography, risk factors, anginal classification, and angiographic data except for smoking history and diabetes
Table III. Early events after $L A D$ artery revascularization

\begin{tabular}{|c|c|c|c|c|c|c|}
\hline & \multicolumn{2}{|c|}{ Group I } & \multicolumn{2}{|r|}{ Group II } & \multicolumn{2}{|c|}{ Group III } \\
\hline & $\%$ & No. & $\%$ & No. & $\%$ & No. \\
\hline Hospital mortality & 6.5 & $4 / 61$ & 5.1 & $3 / 59$ & 1.5 & $2 / 130$ \\
\hline PMI-overall & 8.1 & $5 / 61$ & 10.1 & $6 / 59, p=0.01^{*}$ & 1.5 & $2 / 130$ \\
\hline PMI-LAD & 1.6 & $1 / 61$ & 5 & $3 / 59$ & 一 & \\
\hline PMI-ITA PP & - & & 3.3 & $2 / 59$ & - & \\
\hline PMI-Ao-SV PP & 14 & $1 / 7$ & - & & - & \\
\hline $\mathrm{LCO}$ & 23 & $14 / 61$ & 15 & $9 / 59$ & 16 & $21 / 130$ \\
\hline LABP & 4.9 & $3 / 61$ & 5 & $3 / 59$ & 0.8 & $1 / 130$ \\
\hline
\end{tabular}

Hospital mortality, Thirty-day mortality postoperatively; $P M I$-overall, total incidence of perioperative myocardial infarction; PMI-LAD, incidence of perioperative myocardial infarction located in areas supplied by the LAD artery; PMI-ITA PP, incidence of perioperative myocardial infarction after LAD artery reconstructions with ITA patch; $P M I-A o-S V P P$, incidence of perioperative myocardial infarction after $\mathrm{LAD}$ artery reconstructions with aorta-saphenous bypass graft; $P M I-I T A+S V P P$, incidence of perioperative myocardial infarction after LAD artery reconstructions with saphenous vein patch and an ITA anastomosis; $L C O$, low cardiac output; $L A B P$, intraaortic balloon pumping.

${ }^{*}$ Group II versus group III

(see Table I). The operative characteristics of the patients are depicted in Table II.

There were no intraoperative deaths. Four patient in group I $(6.5 \%)$, three in group II $(5.1 \%)$, and two $(1.5 \%)$ in group III died before hospital discharge $(p=$ not significant) (Table III). The causes of death are summarized in Table IV.

The overall prevalence of perioperative myocardial infarction in groups I, II, and III was $8.1 \%$ $(5 / 61), 10.1 \%(6 / 59)$, and $1.5 \%(2 / 130)$, respectively (group I vs group III, $p=0.055$; group I vs group II, $p=$ not significant; group II vs group III, $p=0.016$ ). Of these, one patient in group I $(1.6 \%)$ and three patients in group II $(5 \%)$ had a perioperative myocardial infarction in the region supplied by the LAD artery. No patients who underwent endarterectomy and extensive patch reconstruction with an ITA had a perioperative myocardial infarction in the LAD artery area. Fourteen (23\%) patients in group I, 9 $(15 \%)$ in group II, and 21 in group III $(16 \%)$ had low cardiac output and needed intraoperative and postoperative inotropic support $(p=$ not significant). The three groups were similar in their need for intraaortic balloon pump support (see Table III).

Follow-up was $98.2 \%$ in group I, $100 \%$ in group II, and $96.8 \%$ in group III, totaling 346.5 patientyears in group I, 319.2 patient-years in group II, and 780.8 patient-years in group III. The mean follow-up period was 6.3 years in group I, 5.7 years in group II, and 6.1 years in group III.

During follow-up $75 \%$ of patients in group I, $79 \%$ in group II, and $78 \%$ in group III were in Canadian 


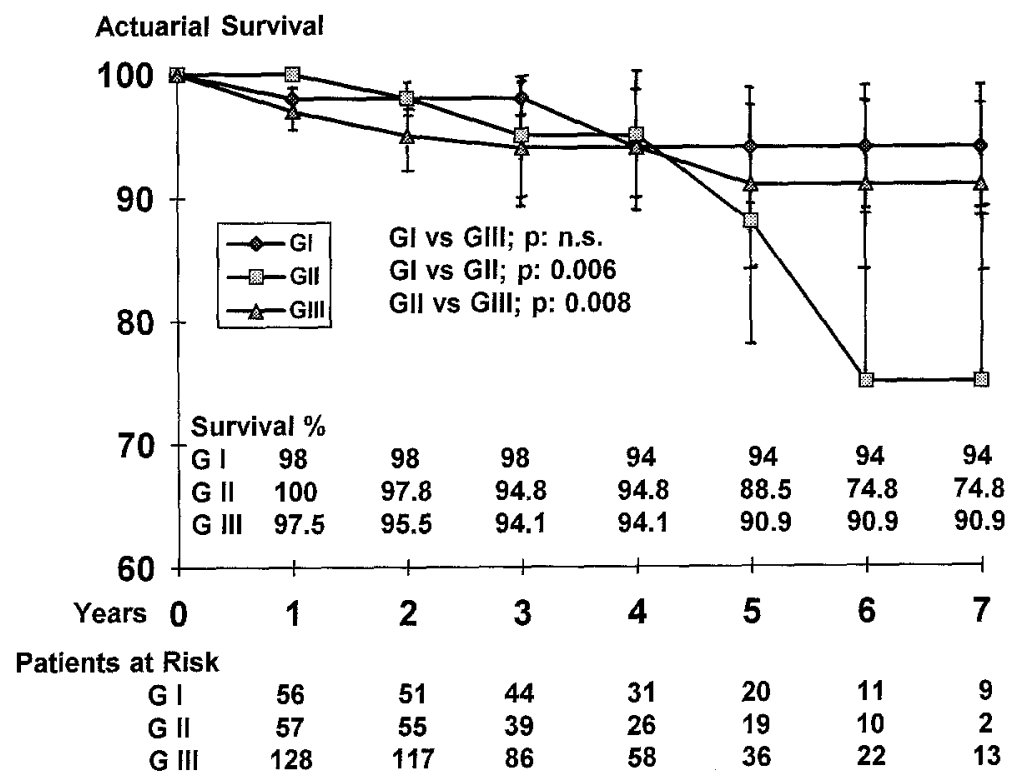

Fig. 1. Actuarial estimates of survival after coronary artery revascularizations with three different techniques. Survival in group I was statistically significantly higher than in group II. Survivals were similar in groups I and III. GI, Group I; GII, group II; GIII, group III; n.s., not significant.

Table IV. Causes of hospital mortality after $L A D$ artery revascularizations with respect to groups and type of reconstruction

\begin{tabular}{|c|c|c|c|c|c|c|c|c|c|c|c|c|}
\hline \multirow[b]{2}{*}{ Cause } & \multicolumn{2}{|c|}{ Group I } & \multicolumn{2}{|c|}{ Group II } & \multicolumn{2}{|c|}{ Group III } & \multicolumn{2}{|c|}{$I T A P P$} & \multicolumn{2}{|c|}{$A o-S V P P$} & \multicolumn{2}{|c|}{$I T A+S V P P$} \\
\hline & $\%$ & No. & $\%$ & No. & $\%$ & No. & $\%$ & No. & $\%$ & No. & $\%$ & No. \\
\hline $\mathrm{LCO}$ & 4.9 & $3 / 61$ & 1.6 & $1 / 59$ & 0.7 & $1 / 130$ & 3.8 & $4 / 104$ & - & - & - & - \\
\hline VF & - & - & 1.6 & $1 / 59$ & 0.7 & $1 / 130$ & 0.9 & $1 / 104$ & - & - & - & - \\
\hline PMI & 1.6 & $1 / 61$ & - & - & - & - & - & - & - & - & 16 & $1 / 6$ \\
\hline MOF & - & - & 1.6 & $1 / 59$ & - & - & 0.9 & $1 / 104$ & 一 & - & - & - \\
\hline Total & 6.5 & $4 / 61$ & 5.1 & $3 / 59$ & 1.5 & $2 / 130$ & 5.6 & $6 / 104$ & - & - & 16 & $1 / 6$ \\
\hline
\end{tabular}

ITA $P$, LAD artery reconstructions with ITA; $A o-S V P P$, Aorta-LAD artery saphenous bypass and patch reconstruction; ITA $+S V P P, \mathrm{LAD}$ artery reconstruction with saphenous vein patch and an ITA anastomosis; $L C O$, low cardiac output; $V F$, ventricular fibrillation; PMI, perioperative myocardial infarction; $M O F$, multiorgan failure.

Cardiovascular Society class I or II ( $p=$ not significant). Two patients in group I, four in group II, and seven in group III died (linearized occurrence rates: $0.6 \% / \mathrm{pt}-\mathrm{yr}, 1.2 \% / \mathrm{pt}-\mathrm{yr}$, and $0.9 \% / \mathrm{pt}-\mathrm{yr}$, respectively). Two patients in group II and one in group III died of recurrent myocardial infarction, and two in group II and another two in group III died of congestive heart failure. One patient in group I and another patient in group III died in automobile accidents. One patient in group III died of a stroke. One patient in group I and two in group III died of unknown causes. Actuarial survivals for 7 years with $95 \%$ confidence limits were $94 \% \pm 5 \%$ in group I, $74.8 \% \pm 16 \%$ in group II, and $90.9 \pm 7.4$ in group III (group I vs group II, $p=0.007$; group II vs group
III, $p=0.008$; group I vs group III, $p=$ not significant) (Fig. 1). Four patients in group II and three in group III had myocardial infarction in the late postoperative period (linearized occurrence rates: $1.2 \% / \mathrm{pt}-\mathrm{yr}$ and $0.4 \% / \mathrm{pt}-\mathrm{yr}$, respectively). Two patients in group III underwent reinterventions (such as coronary angioplasty) (linearized occurrence rate: $0.3 \% / \mathrm{pt}-\mathrm{yr}$ ). Actuarial estimates of freedom from recurrent angina pectoris for 7 years with $95 \%$ confidence limits were $42.7 \% \pm 15.6 \%$ in group I, $33.5 \% \pm 19 \%$ in group II, and $71.9 \% \pm$ $14.2 \%$ in group III (group I vs group II, $p=$ not significant; group II vs group III, $p=0.0001$; group I vs group III, $p=0.03$ ) (Fig. 2). Thirty-four percent of patients in group I, 24\% in group II, and $60.4 \%$ in 


\section{Freedom From Recurrent Angina}

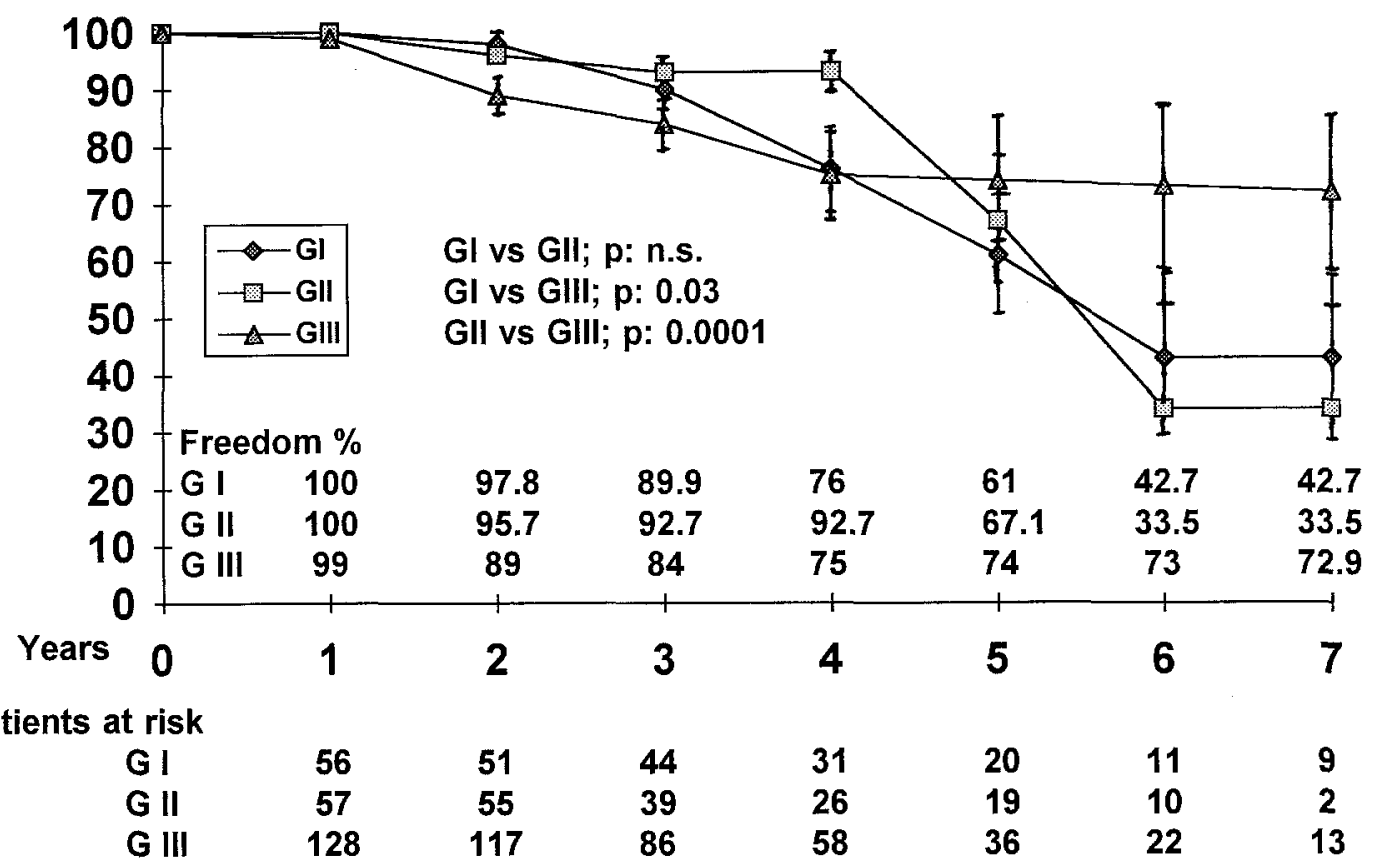

Fig. 2. Actuarial estimates of freedom from recurrent angina pectoris. Recurrent angina apparently is less common in group III patients than in patients from groups I and II. Abbreviations as in Fig. 1.

Table V. Follow-up and late results of all groups

\begin{tabular}{|c|c|c|c|}
\hline & Group I & Group II & Group III \\
\hline Percent follow-up & 98.2 & 100 & 96.8 \\
\hline Mean follow-up (yr) & 6.3 & 5.7 & 6.1 \\
\hline \multirow[t]{2}{*}{ Late mortality, $\%$ (No.) } & $3.5(2 / 57)$ & $7.1(4 / 56)$ & $5.6(7 / 128)$ \\
\hline & $0.6 \% / \mathrm{pt}-\mathrm{yr}$ & $1.2 \% / \mathrm{pt}-\mathrm{yr}$ & $0.9 \% / \mathrm{pt}-\mathrm{yr}$ \\
\hline Class I (\%) & 32 & 35.7 & 37 \\
\hline Class II $(\%)$ & 43 & 43 & 41 \\
\hline Class III-IV (\%) & 25 & 21.3 & 22 \\
\hline \multirow[t]{2}{*}{ Re-MI, \% (No.) } & 0 & $7.1(4 / 56)$ & $2.4 \%(3 / 128)$ \\
\hline & & $1.2 \% / \mathrm{pt}-\mathrm{yr}$ & $0.4 \% / \mathrm{pt}-\mathrm{yr}$ \\
\hline \multirow[t]{2}{*}{ Reintervention, \% (No.) } & 0 & 0 & $1.6 \%(2 / 128)$ \\
\hline & & & $0.3 \% / \mathrm{pt}-\mathrm{yr}$ \\
\hline Employed (\%) & 34 & 23 & $60.4, p=0.0001^{*}+$ \\
\hline \multirow[t]{2}{*}{ Survival at 7 yr (\%) } & $94 \pm 5$ & $74.8 \pm 1.6$ & $90.9 \pm 7.4 p=0.008$ \\
\hline & $p=\mathrm{NS}^{*}$ & $p=0.007 \dagger$ & \\
\hline \multirow[t]{2}{*}{ Angina free $(\%)$} & $42.7 \pm 15.6$ & $33.5 \pm 19$ & $71.9 \pm 14.2$ \\
\hline & & $p=0.0001 \%$ & $p=0.03^{*}$ \\
\hline
\end{tabular}

Class, Anginal class of patients according to the Canadian Cardiovascular Society classification; Re-MI, recurrent myocardial infarction; reintenvention, any nonsurgical revascularization procedure; survival, actuarial survival after 6 years; Angina free, actuarial estimate of freedom from recurrent angina pectoris. Events were presented as proportion of number of events to whole group and actuarial and linearized occurrence rates.

*Group I versus group III.

†roup I versus group II.

\$Group II versus group III.

group III were working actively at late follow-up (group I vs group II, group I vs group III, group II vs group III, $p=0.0001$ ) (Table V).

Follow-up angiograms revealed patency rates of
$81.5 \%$ in endarterectomized LAD arteries of group I patients, $79.1 \%$ in reconstructed LAD segments of group II patients, and $94.4 \%$ in grafts running to the LAD artery of group III patients after mean periods 


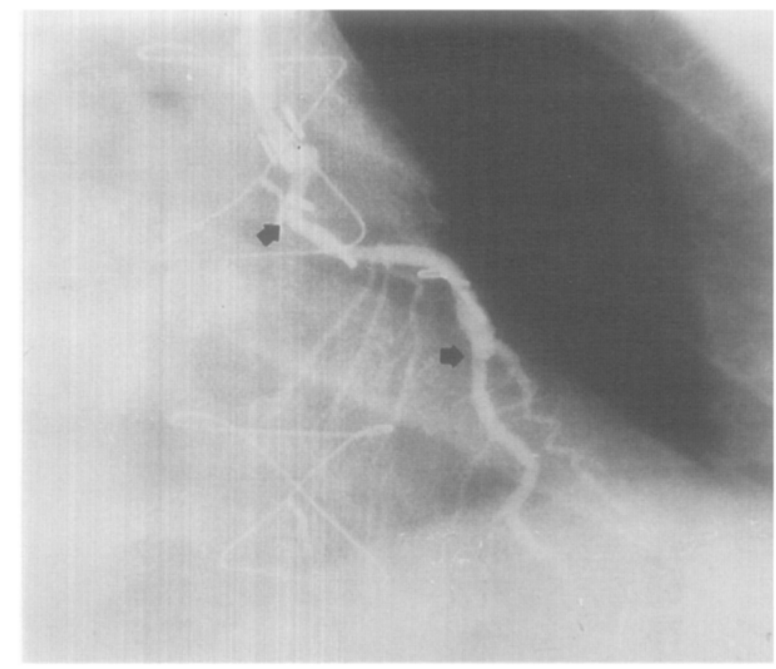

Fig. 3. Coronary angiogram at 32 months in a patient with a $6 \mathrm{~cm}$ long open endarterectomy and patch reconstruction with the distal end of an ITA graft. The endarterectomy and reconstruction site is between the arrows. Regular walls, a lumen with an acceptable width, and good filling of septal perforators are noticeable.

of $6.3,5.7$, and 6.1 years, respectively $(p=$ not significant).

During the evaluation of the angiograms we gave additional emphasis to the patency of septal perforator arteries and their effect on septal wall contractility in patients of groups I and II. Sixty-six percent of the patients who were evaluated angiographically had a patent main septal perforator artery and $58 \%$ had a normally contracting septal wall. Fifty-three percent of patients with occluded septal perforators or in whom endarterectomy was not performed showed akinesia and dyskinesia, whereas the rest showed hypokinesia of the septum.

We compared the angiographic appearance of the extensively endarterectomized LAD artery lumen, material used for patch reconstruction, and functional capacity of patients and noted the following:

1. Most of the grafts with ITA patch reconstructions had a lumen with an acceptable width that did not have ectatic or narrow segments that would result in poor flow characteristics (Fig. 3). A few grafts had shrunken or distorted walls. Some patients had patent endarterectomy segments with a thin or absent lumen of the distal LAD artery and an ITA still patent despite poor runoff. Seven patients in group I had a patent endarterectomy bed with poor distal runoff and no septal perforators visible. Three patients in whom ITAs were used for recon-

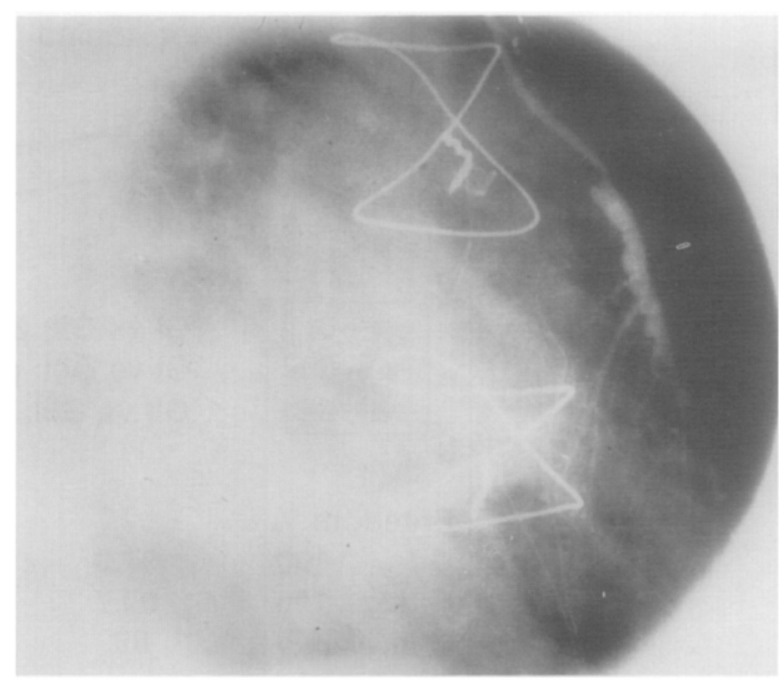

Fig. 4. Coronary angiogram of a patient with open endarterectomy, saphenous vein patch reconstruction, and ITA grafting at 37 months after the operation. There is overt distortion with irregular walls and aneurysmal dilatations at the patch reconstruction site, which is prone to early occlusion.

struction in group I had occluded endarterectomy beds with patent ITAs. Only two ITAs in group I were occluded $(6.6 \%)$.

2. Four patients of six with saphenous vein patch reconstructions and ITA grafting in group I were restudied angiographically. Two of them had an irregular and patulous saphenous vein patch wall and a nearly occluded endarterectomy bed with a patent ITA and an akinetic septal wall. Others had a patent reconstructed LAD artery segment with irregular walls, patent septal perforators, and a normokinetic septum. Extensive aneurysmal dilatations and stenosing areas in the reconstructed segment were noted (Fig. 4).

3. In group I, five patients with saphenous vein bypass grafts to the LAD artery along with endarterectomy and reconstruction were restudied angiographically, and three showed a patent and irregular saphenous vein wall (Fig. 5). No patients in group II who had an LAD reconstruction with the same method underwent coronary angiography.

4. Twenty-four restudies were performed on group II patients with long patch reconstructions with the ITA placed on stenosing plaques. Nineteen reconstructed $\mathrm{LAD}$ artery segments were patent (79.1\%). Most showed regular walls and lumina similar to those of the native artery (Fig. 6).

5. Thirty-four percent of the patients in group I, 


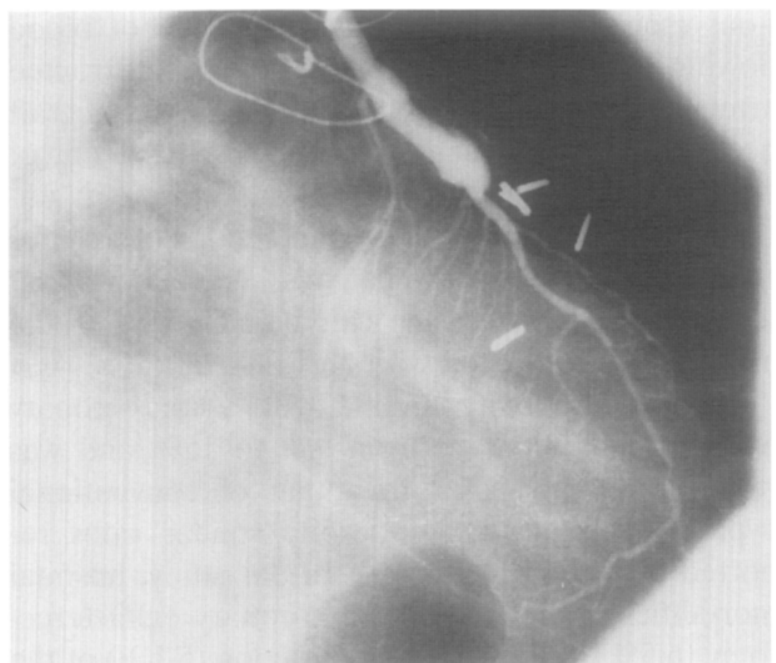

Fig. 5. Coronary angiogram of a patient with open endarterectomy and patch reconstruction with the distal end of an aorta-coronary saphenous vein graft at 2 months after operation. The lumen at the endarterectomy and reconstruction site is irregular and patulous.

$32 \%$ in group II, and $28 \%$ in group III had progression of atherosclerosis of the native coronary artery on coronary angiograms ( $p=$ not significant).

\section{Discussion}

Since the inception of myocardial revascularization, endarterectomies of coronary arteries have been performed with or without CABG. ${ }^{1,3,9}$ After introduction of coronary endarterectomy by Bailey, May, and Lewman, ${ }^{9}$ several techniques and contradictory results were reported. ${ }^{1,-4,9-17}$ Some devices, ${ }^{18}$ both laser $^{19}$ and gas, ${ }^{20}$ were used for endarterectomy.

If an endarterectomy is performed under direct vision with an arteriotomy exposing the whole arterial lumen and side branches containing atherosclerotic occlusive material, and if the occlusive material is then removed without traction, it is possible to avoid residual material in the LAD lumen as well as dissections; both could cause early thrombotic occlusions, perioperative infarctions, and mortality.

Several techniques have been used to reconstruct endarterectomized arteries. At the inception of coronary artery surgery, coronary arteriotomies were closed primarily. ${ }^{4}$ Because of the prevalence of thrombosis, however, this technique was abandoned and arteriotomies were closed with vascular patches. Accelerated atherosclerosis, aneurysmal dilatations, and resultant turbulence of saphenous vein patches also may adversely affect the fate of the reconstruc-

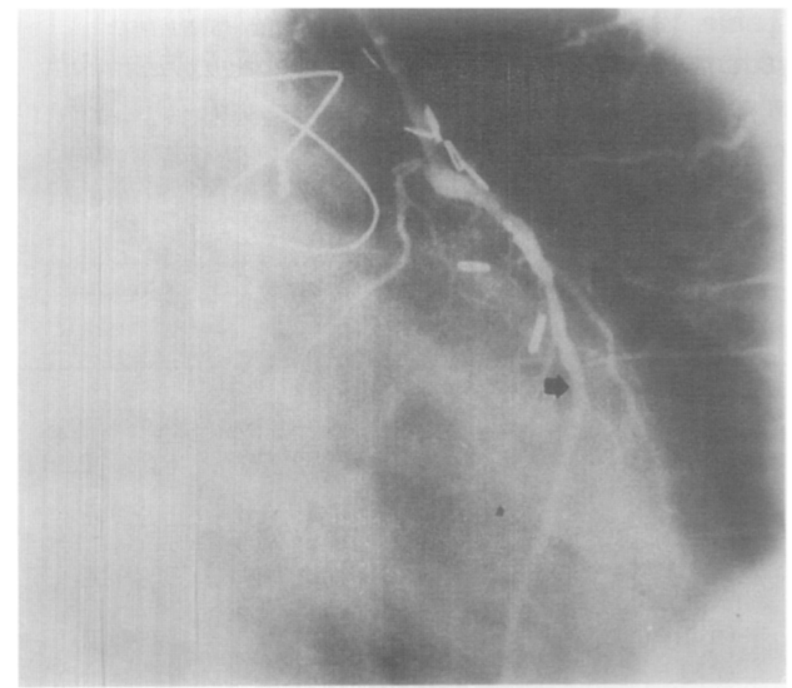

Fig. 6. Coronary angiogram of a patient with patch reconstruction with ITA over a stenosing plaque without endarterectomy. Arrow indicates the end of the patch reconstruction site.

tion. ${ }^{21}$ Whereas ITA grafts have been shown to remain patent in the presence of a negligible forward flow, ${ }^{22}$ reduced flow rates through saphenous vein grafts resulting from extensive LAD artery disease may have a substantial effect on the formation of subendothelial proliferative lesions. ${ }^{23}$ Patch reconstruction of the arteriotomy with an ITA graft is the most common technique in our experience. It offers better coronary flow characteristics, ${ }^{24}$ and the patch is a "live" conduit. ${ }^{25}$ Patch reconstruction provides better vasomotor functions, particularly the capability to adjust the flow rate proportional to the distal runoff, ${ }^{22}$ a widely known paracrine function of a living endothelium that produces and releases prostacyclin and other endothelium-dependent relaxation factors. ${ }^{26}$ The almost negligible incidence of atherosclerotic disease of this conduit is another advantage ${ }^{27}$ Moreover, a better match in diameter with the graft, the reconstructed segment, and the native coronary artery can be obtained with this technique. The resultant flow patterns are better.

Lower patency and higher morbidity rates after coronary artery endarterectomy limit its use to arteries that are inoperable by conventional bypass techniques. ${ }^{1,13-16}$ There are several reasons for worse results of endarterectomy than for conventional anastomoses. Because of the lack of endothelium, all the subendothelial material that can trigger the coagulation cascade is exposed to blood flow. 
Table VI. Angiographic data. Numbers in the parentheses are number of patients angiographically studied. Patency rates of ITA grafts and reconstructed arteries are calculated independently. All comparisons between different subsets revealed statistically insignificant differences.

\begin{tabular}{llllll}
\hline & \multicolumn{2}{c}{ Patent } & & \multicolumn{2}{c}{ Occluded } \\
\cline { 6 - 6 } & $\%$ & No. & & $\%$ & No. \\
\hline Group I $(38 / 57,68 \%)$ & & & & \\
$\quad$ Endarterectomy bed & 81.5 & $31 / 38$ & & 18.5 & $7 / 38$ \\
$\quad$ ITA grafts & 93.4 & $28 / 30$ & & 6.6 & $2 / 30$ \\
Group II $(24 / 56,43 \%)$ & & & & \\
$\quad$ Reconstructed segments & 79.1 & $19 / 24$ & & 20.9 & $5 / 24$ \\
ITA grafts & 87 & $20 / 23$ & 13 & $3 / 23$ \\
Group III (18/128, 14\%) & & & & \\
$\quad$ Grafts to LAD artery & 94.4 & $17 / 18$ & & 5.6 & $1 / 18$ \\
ITA PP & 90.5 & $48 / 53$ & 9.5 & $5 / 53$ \\
Ao-SV PP & 50 & $2 / 4$ & 50 & $2 / 4$ \\
ITA+SV PP & 60 & $3 / 5$ & 40 & $2 / 5$ \\
\hline
\end{tabular}

ITA PP, LAD artery reconstructions with ITA; AO-SV PP, aorta-LAD artery saphenous bypass and patch reconstruction; ITA $+S V P P$, LAD artery reconstruction with saphenous vein patch and an ITA anastomosis.

Some platelet aggregation and fibrin clot formation occur in all cases if flow through the lumen is sufficient. ${ }^{28}$ With poor distal runoff, however, this clot formation progresses rapidly with resultant thrombosis of the lumen caused by stagnation of blood. The absence of substances released from the endothelium, such as prostacyclin and nitric oxide, which prevent platelet adhesion and aggregation, may further contribute to early occlusion. The closed endarterectomy technique may result in dissection of the endarterectomized edges, and the residual atherosclerotic material in the lumen may result in early or late occlusion. Some authors emphasized the importance of removal of the endarterectomy core with good tapering ends to prevent dissection. ${ }^{1-3}$ We also observed that septal wall motion was worse in patients in whom the septal perforators were occluded than in patients with patent septal arteries.

The diameters of the reconstructed artery, the distal native artery, and bypass graft are also important. Patency of the bypass graft has been shown to be related to the diameter and flow in the endarterectomized vessel..$^{21,29,30}$ Usually the reconstructed segment is wider than the native artery and is dependent on the technique and material used. Because of the lack of viable properties and low smooth muscle content of the vessel wall, a saphenous vein patch can easily form aneurysmal dilata- tions (see Fig. 4). Resultant turbulence of blood flowing from the bypass graft to the reconstructed artery and distal bed increases the likelihood of graft occlusion. ${ }^{21}$ Our experience confirms this point of view. We have not observed these kinds of dilatations on follow-up coronary angiograms of arteries reconstructed with ITA patches. We believe that ideal flow characteristics can be achieved if the artery is reconstructed with an ITA graft.

Hospital mortality after CABG with coronary endarterectomy varied from $4 \%$ to $15 \%$ and was reported to be higher than that of conventional bypass techniques, ${ }^{1,13-16}$ despite similar rates reported by some authors. ${ }^{10-12}$ In our study, hospital mortalities after $\mathrm{CABG}$ with coronary endarterectomy $(6.5 \%)$ and patch reconstruction $(5.1 \%)$ of the LAD artery were comparably higher than after conventional bypass $(1.5 \%)$, although the difference did not reach statistical significance.

The rate of perioperative myocardial infarction after coronary endarterectomy was reported to range between $5.6 \%$ and $13.1 \%$ and was generally twice that for CABG alone. ${ }^{1,9}$ In our series, the overall perioperative myocardial infarction rate in patients with patch reconstructions without an endarterectomy was statistically significantly higher than in patients having conventional bypass $(10.1 \%$ vs $1.5 \%, p=0.016$ ); by contrast, the difference between the open endarterectomy group and the conventional bypass group did not reach statistical significance ( $8.1 \%$ vs $1.5 \%, p=0.055$ ). If only areas supplied by the LAD artery were taken into account, the perioperative myocardial infarction rate in the coronary endarterectomy group was only $1.6 \%$ and was lower than the rate in group II patients $(1.6 \%$ vs $5 \%, p=$ not significant). Residual atherosclerotic material in the distal anastomosis and incomplete revascularization may be the reason for the higher perioperative myocardial infarction rates in patients who underwent patch reconstructions over atherosclerotic plaques.

Brenowitz, Kayser, and Johnson ${ }^{1}$ reported a $72.6 \%$ late patency rate an average of 31 months after saphenous vein reconstruction of the LAD artery after coronary endarterectomy. Qureshi and associates reported the same rate in 58 patients with symptomatic disease. Our late patency rates in patients having $\mathrm{LAD}$ reconstructions $(81.5 \%$ in group I and $79.1 \%$ in group II) were not statistically significantly lower than the patency rates of grafts to the LAD artery in the conventional bypass group (94.4\%, $p=$ not significant), which demonstrates 
superiority of ITA patch reconstruction. Furthermore, the patency rates of ITA grafts anastomosed to diseased arteries with poor runoff in group I and II patients were similar to the patency rates of the ITA grafts in the conventional group (93.4\%, 87\%, and $94.4 \%$ in groups I, II, and III, respectively).

Actuarial survival after CABG with left coronary endarterectomy was reported to vary between $46.5 \%$ and $92.5 \%$ at 5 years, depending on risk factors. ${ }^{1}$ Two patients in group I, four in group II, and seven in group III died during the late postoperative period. The late mortality in group I was probably not related to heart disease, whereas in groups II and III it often was. Actuarial survival of patients with coronary endarterectomy was better than that in patients with patch reconstructions over plaques at 7 years $(94 \%$ vs $74.8 \%, p=0.008)$. This feature was probably a reflection of the complete removal of all atherosclerotic material and complete revascularization of the $\mathrm{LAD}$ artery in group I patients.

On the other hand, the actuarial estimate of freedom from recurrent angina over the long term was significantly higher in group III (see Fig. 2). However, life expectancy, functional capacity, and working status of patients who underwent endarterectomy and repair is reasonable and comparable with those in group III.

\section{Conclusion}

The increased complication rate after $\mathrm{CABG}$ with coronary endarterectomy simply reflects the severe and often diffuse nature of the CAD in these patients. It is crucial to remove all atherosclerotic material under direct vision with open endarterectomy, paying attention to open orifices of septal perforator arteries during the procedure. Our results confirm the superiority of LAD artery reconstruction. Grafting with an ITA associated with careful endarterectomy technique for coronary revascularization yields acceptable early and longterm results. Because of the natural history of this disease, the opportunity for a lifesaving operation should be offered to patients who have otherwise inoperable diffuse disease of the LAD artery.

\section{REFERENCES}

1. Brenowitz JB, Kayser KL, Johnson WD. Results of coronary artery endarterectomy and reconstruction. J Thorac Cardiovasc Surg 1988;95:1-10.

2. Shapira N, Lumia FJ, Gottdiener JS, Germon P, Lemole GM. Adjunct endarterectomy of the left anterior descending coronary artery. Ann Thorac Surg 1988;46:289-96.
3. Ladowski JS, Schatzlein MH, Underhill DJ, Peterson AC. Endarterectomy, vein patch, and mammary bypass of the anterior descending artery. Ann Thorac Surg 1991;52:1187-9.

4. Parsonnet V, Gilbert L, Gielchinsky I, Bhaktan EK. Endarterectomy of the left anterior descending and mainstem coronary arteries: a technique for reconstruction of inoperable arteries. Surgery 1976;80:662-73.

5. Campeau L. Grading of angina pectoris. Circulation 1976;54: 522-3.

6. Blackburn H, Keys A, Simonson E, Rauthaharju P, Punsai S. The electrocardiogram in population studies: a classification system. Circulation 1960;21:1160-75.

7. Bodnar E, Haberman S, Wain WH. Comparative method for actuarial analysis of cardiac valve replacements. Br Heart J 1972;42:541-52.

8. Grunkemeier G, Starr A. Actuarial analysis of surgical results: rationale and method. Ann Thorac Surg 1977;24: 404-8.

9. Bailey CP, May A, Lewman WM. Survival after coronary endarterectomy in man. JAMA 1957;164:641-6.

10. Groves LK, Loop FD, Silver GM. Endarterectomy as a supplement to coronary artery saphenous vein bypass surgery. J Thorac Cardiovasc Surg 1972;64:514-22.

11. Cheanvechai C, Groves LK, Reyes EA, Shirey EK, Sones FM. Manual coronary endarterectomy. I Thorac Cardiovasc Surg 1975;70:524-8.

12. Hochberg MS, Merrill WH, Michaelis LL, McIntosh CL. Results of combined coronary endarterectomy and coronary bypass for diffuse coronary disease. J Thorac Cardiovasc Surg 1978;75:38-46.

13. Dumanian AV. Endarterectomy of the branches of the left coronary artery in combination with aorta to coronary artery reversed saphenous vein graft. J Cardiovasc Surg (Torino) 1974:15:154-7.

14. Livesay JJ, Cooley DA, Hallman GL, Reul GL, Ott DA, Duncan JM, et al. Early and late results of coronary endarterectomy: analysis of 3369 patients. J Thorac Cardiovasc Surg 1986;92:649-60.

15. Keon WJ, Masters RG, Koshak A, Hendry P, Farrel EM. Coronary endarterectomy: an adjunct to coronary artery bypass grafting. Surg Clin North Am 1988;68:669-78.

16. Minale C, Nikol S, Zander M, Uebis R, Effert S, Messmer BJ. Controversial aspects of coronary endarterectomy. Ann Thorac Surg 1989;48:235-41.

17. Qureshi SA, Halim MA, Pillai R, Smith P, Yacoub MH. Endarterectomy of the left coronary system: analysis of a 10 year experience. J Thorac Cardiovasc Surg 1985;89:852-7.

18. Izzat MB, Angelini GD. How to do it. A modified battery powered toothbrush for coronary artery endarterectomy. J Cardiovasc Surg 1993;34:527-8.

19. Olivier JP, Gandjbakhch I, Avrillier S, Delettre E, Bussiere JL, Cabrol C. Intraoperative coronary artery endarterectomy with excimer laser. J Thorac Cardiovasc Surg 1990;100:60611.

20. Sawyer PN, Pasupathy CE, Fitzgerald J, Kaplitt MJ, Costello M, Keates JR, et al. Six-year follow-up study in the use of gas endarterectomy. Surgery 1972;72:837-48.

21. Imparato AM, Bracco A, Kim GE, Zelf R. Intimal and neointimal fibrous proliferation causing failure of arterial reconstructions. Surgery 1972;72:1007.

22. Nasu M, Takashi A, Akasaka T, Shinkai M, Fujiwara H, Sono 
J, et al. Postoperative flow characteristics of left internal thorasic artery grafts. Ann Thorac Surg 1995;59:154-62.

23. Faulkner SL, Fisher RD, Conkle DM, Page DL, Bender HW. Effect of blood flow rate on subendothelial proliferation in venous autografts used as arterial substitutes. Circulation 1975;51,52(Suppl):I163-71.

24. Fusejima K, Takahara Y, Sudo Y, Murayama H, Masuda Y, Inagaki $\mathrm{Y}$. Comparison of coronary hemodynamics in patients with internal mammary artery and saphenous vein coronary artery bypass grafts: a noninvasive approach using combined two dimensional and Doppler echocardiography. J Am Coll Cardiol 1990;15:131-9.

25. Singh RN. Sosa JA. Internal mammary artery: a "live" conduit for coronary bypass. J Thorac Cardiovasc Surg 1984:87:936-8.

26. Lïscher TF, Diederich D, Siebenmann R, Lehmann K, Stulz $P$, von Segesser $L$, et al. Difference between endothelium dependent relaxations in arterial and in venous coronary bypass grafts. N Engl J Med 1988;319:462-7.

27. Mestres CA, Rives A, Igual A, Vehi C, Murtra M. Atherosclerosis of the internal mammary artery: histopathological analysis and implications on its results in coronary artery bypass graft surgery. Thorac Cardiovasc Surg 1986;34:356-8.

28. Walley VM, Byard RW, Keon WJ. A study of the sequential morphologic changes after manual coronary endarterectomy. J Thorac Cardiovasc Surg 1991;102:890-4.

29. Parsonnet V, Gilbert L, Gielchinsky I. A prognostic index for prediction of aortocoronary bypass graft closure with special reference to endarterectomy. In: Norman JC, editor. Coronary artery medicine and surgery: concepts and controversies. New York, Appleton-Century-Crofts, 1975:607-12.

30. Morton BC, Beanlands DS, Chambers RJ, et al. Fate of the graft and native vessel after endarterectomy of the left anterior descending artery. Can J Surg 1979:142-4. 